\title{
Prevalence of sexual harassment among Norwegian female elite athletes in relation to sport type
}

by

Professor Kari Fasting, Norwegian University of Sport and Physical Education Professor Celia Brackenridge, independent researcher \& University of Huddersfield, UK

Professor Jorunn Sundgot-Borgen, Norwegian University of Sport and Physical Education

Correspondence to be sent to: Professor Kari Fasting

The Norwegian University of Sport and Physical Education

Box 4014 Ullevål Stadion 0806 Oslo Norway

E-mail= kari.fasting@nih.no

Phone +4723262405

Fax +4723262414 


\begin{abstract}
Although it is often assumed that the prevalence of sexual harassment is different in different sports, this assumption has not been empirically tested. This study considers whether the experience of sexual harassment varies by sport. The female elite athletes $(\mathrm{N}=$ 553) in the study participated in 56 different sport disciplines. These were grouped as follows :1) team or individual sports; 2) extent to which clothing required for competition is revealing ; 3) gender structure (male-or female dominated membership statistics); and 4) gender culture (masculine, gender-neutral, or feminine). The data show that sexual harassment occurs in every sport group. Female elite athletes who participated in 'masculine' sports appear to experience more harassment than women in the other groups. We conclude that, when it comes to female athletes' experiences of sexual harassment, sport type matters far less than sport participation per se.
\end{abstract}

Key words: sexual harassment, female elite athlete, sports groups 
Research on sexual harassment is relatively recent, with most studies taking place only in the past two decades (Wise \& Stanley, 1987; Stockdale, 1996; O’Donohue, 1997) with the focus mainly on workplace and educational settings. Gender ratios, sexualized atmospheres, and organizational power have been found to influence both the incidence and maintenance of sexual harassment in these settings (Hotelling \& Zuber, 1997). Given these findings, is would be surprising if sexual harassment did not also occur in sport organizations. Sexual harassment prevalence rates are highest in workplaces where women have been traditionally underrepresented (Gutek, 1985) and lowest in those workplaces dominated by women (Grauerholz, 1996). Since most sport organizations are male dominated , and seem grounded in masculinity and 'traditional male values', it is possible that sexual harassment is also prevalent .

Research on sexual harassment in sport is limited but does include both qualitative investigations (e.g., Brackenridge, 1997; Cense 1997) and quantitative surveys (e.g., Holman, 1995; Volkwein et al., 1997) with some studies using both approaches (e.g., Kirby \& Greaves, 1996; Leahy et al., 2001). The qualitative studies have been used to gather descriptions of athletes’ experiences and to analyze risk factors (e.g., Brackenridge, 1997; Cense \& Brackenridge, 2001). The quantitative investigations in sport have often used relatively small samples and have frequently attracted low response rates; for example Kirby and Greaves (1996) achieved 22 per cent, and Leahy et al. (2002) only 18 per cent. As with studies of sexual harassment in general, the sport studies are difficult to compare because they vary in terms of the definitions adopted, sampling procedures, validity and reliability, underreporting/non-response and so on (Brackenridge, 2001:49-53).

The overall aim of this type of research has been to produce knowledge of practical use for the prevention of harassment and abuse, so the identification of specific risk factors has been very important. But no studies have yet attempted to identify risk sport-by-sport. The 
main question addressed here, therefore, is: Does experience of sexual harassment vary according to different types of sports?

\section{Specifying sexual harassment risk in sport: Ethical and political limitations}

One of the questions most frequently asked of sexual harassment researchers in sport is "Which sports are most risky?" This question has clear political and policy connotations. The answer could be used to inform both prevention work and the development of good practice. Equally, it could be used to scapegoat sports that have particular difficulties with harassment and could even lead to parents removing their children from the sports. There is already evidence of one sport in the UK losing $£ 1$ million worth of sponsorship after an infamous case of sexual abuse (Sparkes, 1999). The dangers of fuelling further a moral panic over harassment in sport are clear. Both false positives (identifying harassment where none occurred) and false negatives (failing to identify harassment when it does occur) have very serious consequences for individuals and sport organizations. There is also the possibility that sports not listed as 'risky' might consider themselves, unjustifiably, to be safe and thus fail to introduce or take prevention measures. At this stage there is very little information available on which to make accurate evaluations of sport-specific risks of sexual harassment. Overall, then, sport researchers have been reluctant to name specific sports in their analyses of sexual transgression, both to protect the anonymity of all concerned, and to avoid giving undue cause for complacency.

Another danger in focusing on specific types of sport in the identification of risk is that it leads to a partial and possibly deterministic analysis, restricting the range of situational factors and overlooking completely the athlete and perpetrator factors that lead to sexual exploitation. In the analysis that follows, therefore, it is worth remembering that sport type is only one variable in the range of factors that are associated with the sexual exploitation of athletes. 


\section{Defining sport types}

Many simple sport groupings are in common usage, for example individual/team or masculine/feminine sports. The rules of classification require that categories should be discrete and equivalent in order for meaningful analysis to be undertaken. The taxonomic task is made more difficult by the wide variation in purposes, for example motivation to participate (Kenyon, 1968), gender-appropriateness (Metheny, 1963), pedagogic analysis (Mauldon \& Redfern, 1981), and activity design and modification (Brackenridge \& Alderson, 1983). In their attempt to define age-related risk for sexual abuse in sport, Brackenridge and Kirby (1997) developed an age-based taxonomy in which early-peaking sports (around the Stage of Imminent Achievement) were hypothesized to present higher risk. The structure of sport, its rules and techniques, is another possible factor related to athletes' susceptibility to sexual harassment or abuse -- for example, the amount of touching required in order to coach particular techniques, or the extent to which sports clothing reveals the body in different disciplines.

One method of protecting the identities of individual sport disciplines is by aggregating them into groups or types, thus allowing generalizations to be made against specific criteria without the need to name particular sports. Popular assumptions about sexual harassment in sport, frequently expressed in the media and at coaching workshops, are that it is more prevalent in sports where athletes are relatively isolated from each other (that is individual sports), where clothing is more revealing, where the sport culture involves stereotypical displays of femininity and where the organizational structure is male-dominated. This study tests these assumptions by dividing the different sport disciplines according to the following criteria (Table 1):

1. Formation of the sport - team or individual. 
2. Extent to which the sport's clothing is revealing (a little, a moderate amount, or a lot). This judgment, admittedly subjective, was made on the basis not only of the amount of clothing but also its closeness of fit to the body.

3. Gender structure (male- or female-dominated membership statistics). Official membership statistics from the Norwegian Olympic Committee and Confederation of Sport were used (NOCCS, 1999). Sport federations were divided into: 'female-dominated' (with more than 50\% female members), 'clearly male-dominated' (with more than $80 \%$ male members). Sports not meeting these criteria were considered to be 'neutral'. Males dominate most sports, but in Norway there were a few sports in which the female membership accounted for more than 50 per cent. Our objective was to determine whether a female dominated environment would have any prevention effect and thus reduce the prevalence of sexual harassment. Similarly, we wanted to determine whether the opposite was the case, but since most sports are dominated by men a high (80 per cent) cut off point for male domination was chosen to focus on those sports that were clearly the most male-dominated.

4. Gender culture ('masculine', 'gender-neutral' or 'feminine'). Here the categorization presented by Koivula (1995) was adopted, based on the results from her Swedish study which examined gender labeling of different sports. For reasons of confidentiality only aggregated data are presented and discussed below. It is clear from Table 1 that the different sports groupings are culturally specific and that, in some cases, the disciplines appear anomalous because they come from aggregated federations; for example, hammer throwing is in the track and field federation with an overall 'neutral' gender structure even though it might be thought to be a masculine discipline. 


\section{Method}

We report selected findings from Phase I of a study of elite female athletes’ experiences of sexual harassment and abuse both within and outside of a sport setting, conducted in Norway from 1997-99. ${ }^{1}$ This is part of a much larger survey study of disordered eating and attitudes towards doping . ${ }^{2}$

\section{Sample}

Elite athletes who participated in this study were defined as those who qualified for the national team at junior or senior levels, or as a member of a recruiting squad for these teams. A total of 660 female athletes aged 15-39, across 56 sport disciplines, were invited to participate in the research. The data reported here relate only to comparisons of the prevalence of sexual harassment between different sub-groups of the athletes, since the purpose of this particular analysis is to examine variations between sport types. The researchers recognize that male athletes in the same age group as this sample, and athletes under 15 years old of both sexes, may also be subjected to sexual harassment and abuse, but as part of the Norwegian Women Project this study is limited to the 15-39 year old sample of elite female athletes.

Procedure

Data were collected via a postal questionnaire in the autumn of 1997. Target participants who did not answer the questionnaire were sent a duplicate, and some athletes were contacted personally by telephone. Experiences of sexual harassment were measured through an 11-item list of descriptions, derived and adapted from Brackenridge’s (1997) original definitions of sexual harassment and sexual abuse. The items ranged from mild harassment such as “repeated unwanted sexual remarks concerning one’s body, private life, sexual orientation etc.” to severe sexual abuse defined as “attempted rape or rape.” 
Respondents were asked to mark against each of the 11 items whether they had experienced it or not, and whether it had been perpetrated by a man or a woman. The athletes were also asked to indicate if they had experienced the harassment from an authority figure ${ }^{3}$ in sport, from peers in sport, or from someone outside sport.

A total of 572 athletes (87 per cent) completed the questionnaire. It is not clear why such a comparatively high response rate for a study of sexual harassment in sport was achieved. One possible explanation is that the research project was supported by both the Norwegian Olympic Committee and also by the athletes’ own sport federations, although both Kirby and Greaves (1996) and Leahy et al. (2000) had similar institutional backing yet achieved much lower response rates. Perhaps the fact that the whole project was initiated as a means of helping athletes with problems (e.g., in relation to eating disorders, nutrition and so on) may have encouraged more responses. Also , the fact that this questionnaire was not only about sexual harassment, but was mainly about eating disorders and attitudes towards doping, may also have helped to encourage returns. Even so, 19 respondents chose not to complete the questions on sexual harassment. Consequently, the findings reported below are based on answers from 553 athletes.

\section{Representativeness, validity and reliability}

The sensitivity of sexual harassment as a theme can be expected to influence response rates but, as already noted, the response rate in this study was very high. Yet there were still some women who did not return the questionnaire. The question arises, therefore, whether these missing individuals were special in some way and/or if they did not reply because of the questions about sexual harassment. This seems unlikely, however, since the sexual harassment section occupied only one page in the overall questionnaire, which was mainly about eating habits, menstruation and doping. Thus, there is no reason to believe that the sample is not representative of Norwegian female elite athletes. 
Underreporting is a typical problem with difficult and sensitive themes such as sexual harassment and abuse, so it may have affected this study. Memory attrition or suppression is also associated with studies that ask about sexual harassment experiences, especially in relation to its more serious forms. Also, since the participants were told that they might be interviewed and tested later, the study was not anonymous and this might have compounded underreporting, especially about serious forms of sexual harassment, and perhaps particularly if this had taken place within a sport setting. ${ }^{4}$

In view of the fact that the measure of sexual harassment was limited, and that the study might suffer from underreporting, it was decided that the results should be presented by comparing experiences of sexual harassment between different sub-groups among the athletes, as outlined above. The results reported below are based on a threshold measure, not a quantity, severity or frequency measure; in other words, any reported sexual harassment was counted, regardless of type of experience. Where the results 'experiences of sexual harassment' are presented this therefore means that a respondent marked one or more forms of sexual harassment on the 11-item scale: it does not indicate the severity, or the number of those experiences. ${ }^{5}$ It should be noted that very few 'serious' sexual harassment experiences were identified by the survey overall. The decision not to analyze either frequency or severity of experience here is based on the small cell sizes that would be available if the data were sub-divided yet again under the four criteria already outlined.

\section{Ethical considerations}

All subjects participating in the study completed a consent form. Written parental consent was also obtained from those under 18 years of age. Clearance for the study was gained from the Norwegian Olympic Committee (NOC), the Data Supervising Bureau, and the Regional Committee for Medical Research Ethics in Oslo. All potential participants were informed that participation was voluntary. Although the study as such was not anonymous, 
since interviews were requested of some of the respondents for Phase II, all respondents were guaranteed confidentiality in the handling and presentation of the data.

In recognition of the potential emotional distress that this survey might cause, the researchers secured permission to include in the questionnaire the telephone number for the national crisis center for women in Oslo.

\section{Results and discussion}

The responding athletes were all members of the squad of a junior, a development or a senior national team. Only 73 had never represented Norway in an international competition. Altogether, 153 had been on their national team for five or more years and 43 per cent $(n=$ 237) had participated in either a world championship and/or in the Olympic Games. Several of them were among the best athletes in the world in their sports and as many as 121 had received a medal in a world championship or in the Olympics. About 50 per cent reported that they practised for 11 - 20 hours per week in preparation for the competitive season. Most were students ( $\mathrm{n}=337,61$ per cent) but 41 (7 per cent) were full time athletes, 106 (18 per cent) full time workers and 69 (13 per cent) part time workers. Almost half the elite athletes lived with their parents and 22 per cent with their husband or partner.

The main result , in relation to different sports disciplines, is that sexual harassment occurs in almost every sport group and is not specific to any particular type. Earlier analysis of the data revealed that more than half of the athletes (51 per cent) had experienced one or more forms of sexual harassment (Fasting, et al., 2000). That earlier analysis also showed that the athletes had been exposed to sexual harassment more often from someone outside sport (39 per cent) than in a sport setting (28 per cent), that 15 per cent of the total sample had experienced sexual harassment from an authority figure in sport and 19 per cent from peer athletes (see the Totals in Tables 2a and 2b) (Fasting, et al., 2000).

\section{[Tables 2a and $2 b$ about here]}


No significant differences were found in the level of reported sexual harassment between the athletes participating in individual and team sports, either overall, or in- and outside a sport setting (Table 2a). The classification of team versus individual sport thus appears to be meaningless in regard to harassment since many athletes from so-called individual sports practice or compete in group settings and athletes from so-called team sports can readily be isolated by authority figures with malintent.

\section{[Tables 3a and $3 b$ about here]}

No significant differences in the level of reported sexual harassment were found between the sport groups when compared with the extent to which their sport clothing was revealing (Tables 3a and 3b). Showing body contours and/or skin in sport does not appear to elicit sexual harassment and there is apparently no link between scant clothing and sexual harassment. This finding confounds commonsense explanations of harassment and should give pause for thought to those who assume that extensive clothing cover protects against harassment. However, it is not necessarily a reason for ceding to pressure from those administrators who want women athletes to wear less and less clothing when they compete (www.dagsavisen.no/sport/2004/01/774755.shtml, 2004).

\section{[Tables 4a and $4 b$ about here]}

In relation to gender structure (Table $4 \mathrm{a}$ and $4 \mathrm{~b}$ ), there was no difference in the reported sexual harassment of athletes from sport organizations with a skewed gender ratio among their membership. It was anticipated that female members of male-dominated sport organizations would have experienced more sexual harassment but that was not found in this study. Whether this would be the case in countries with a less extensive social history of gender equality is worthy of investigation.

[Tables $5 a$ and $5 b$ about here] 
Gender culture, for the purposes of this analysis, was determined by a subjective rather than objective criterion, that is the social construction of masculinity and femininity which is historically and culturally contingent. For the total group, those in 'masculine' sports had a higher reported experience of harassment than those in the other two groups $(\mathrm{p}<0.013)$ ('feminine' and 'gender-neutral') (Table 5a). This occurred, however, only among those who had experienced sexual harassment outside sport $(\mathrm{p}<0.005)$, which might indicate a negative perception by people outside sport towards female athletes who take part in sports perceived as ‘masculine’ (cf., Lenskyj, 1986; Griffin, 1998).

The tendency for women in 'masculine' sports to report harassment more than women in the other groups also occurred among those who had been harassed by peer athletes but not by those who had been harassed by authority figures $(\mathrm{p}<0.046)$ (Table 5b). This might be because authority figure are already committed to the sports they coach, so they do not find it unusual for women to be involved in these sports. Peer athletes may be more ambivalent about this, especially if they come from other sports (something that was not measured in this study).

There are two possible explanations why female athletes participating in 'masculine' sports are more likely to report experiences of sexual harassment than athletes in 'gender neutral' and 'feminine' sports. First, they enter sport cultures which are already dominated by 'traditional masculine values', and which may be more tolerant of sexual harassment. Second, perhaps the need to exhibit power over women, as a part of a male identity, (also defined as 'patriarchal power') is reinforced by the entrance of women into 'traditionally' male sports. This may happen regardless of whether the harassment takes place inside or outside a sport setting, but our data indicate that this is especially the case for harassment from outside the sport setting. 
Further analysis of those taking part in 'masculine' sports shows that almost half (46 per cent) of those who were in individual sports with a 'neutral' gender structure reported experiences of sexual harassment. The next highest percentage (43 per cent) was for those in 'masculine' team sports from male dominated organizations. One possible explanation for this is that women playing in male-dominated cultures and gender neutral sport structures operate under received patriarchal values and norms. Those women who play masculine sports might well require the protection of female dominated structures in order to resist the worst traditions of patriarchy. In other words, numerical distribution by gender is not proportional to gender-cultural experience.

Our main finding is that sexual harassment occurs in all sport groups. Thomas (1997) suggests that psychologists' explanations of sexual harassment have focused on the motivation and feelings of the individual harasser, whereas sociologists' explanations have focused sexual harassment as a manifestation of a wider system of asymmetrical power relations between men and women. While Thomas recognizes that all actions are influenced by the norms and values in a society or a social group, she argues for a combination of psychological and sociological perspectives in this field because it is important for men to be responsible for their own actions, rather than 'blaming the system'.

Notwithstanding the fact that males are sometimes victims of harassment and that females can be perpetrators, a common factor in most reported sexual harassment of females is the exercise of male power over women, and it is from this perspective that the results presented here can be best understood. The normalizing of sexual harassment that has been shown in some studies, also in sport (Tomlinson \& Yorganci, 1997) - that is that 'boys will be boys' or 'this is just the way this coach is' - should also be understood in this way. Proving one’s masculinity by objectifying women through sexual harassment may also be a way of reinforcing a heterosexual identification with other men. Sport is an important site where such 
learning takes place. According to Messner and Sabo (1994:9) sport is "an institution created by and for men...it has served to bolster a sagging ideology of male superiority and has thus helped to reconstitute masculine hegemony in the $19^{\text {th }}$ and $20^{\text {th }}$ century.” Adherence to the process of man-making through sport, or what Messner (1992) calls a "cultural masculinity rite”, is still one of the most pervasive features of contemporary western culture. Sport has also been described as one of the few areas where 'men still can be men', and where women are considered intruders. Curry (1991), for example, found that male athletes' talk in the locker room often treated women as objects, encouraged sexist attitudes toward women and, in extreme cases, promoted rape culture. There are also other accounts of the hyper-masculine heterosexual culture of sport, with sexually intense initiation rituals, and demeaning attitudes towards women (Kirby et al., 2000; Robinson, 1998). By participating in 'masculine’ sport women are entering one of the few arenas that men still had to themselves and where they could demonstrate and reinforce their superiority over women.

\section{Conclusions}

Assumptions about the risk of sexual harassment being higher in some sports than others lead not only to distorted stereotypes but also to incorrectly targeted policies for harassment-free sport. The results of this study challenge some popular ideas about sexual harassment and the nature of sport risks. They also confirm some earlier research on the contribution of gender cultures to the generation and maintenance of the sexual stereotypes that underpin harassment.

The results raise interesting questions about the persistence of gendered structural relations in sport, despite the arguments of some sport sociologists that we have moved into a post-structural era. Whether this is associated with the cultural time lag that applies to sport, the inherent conservatism of the institution or other reasons is unclear but it certainly poses a 
challenge to the argument that 'difference' has replaced 'inequality' as a theoretical and practical construct.

These findings pose a serious challenge to those who argue that structural relations are no longer important in sport; they indicate that gender hierarchies in sport are still inexorably linked to female athletes’ experiences of sexual harassment, regardless of sport group. When it comes to female athletes' experiences of sexual harassment, sport type seems to matter far less than sport participation per se, and those women engaged in sports perceived to be 'masculine' are more likely to report harassment than other female athletes.

Note: An earlier version of this paper was presented to the Pre-Olympic Scientific Congress in Brisbane, Australia, September, 2000.

Acknowledgements: The authors wish to acknowledge the role of Norwegian Olympic Committee in commissioning and funding this project, and also wish to thank the Norwegian University of Sport and Physical Education for their continuing support of this research. Anne Marte Pensgaard worked on the earlier statistical analysis and Kristin Walseth and Hanne Overlier also assisted with the research. Thanks also to the editor and three anonymous reviewers for comments on an earlier draft.

\section{Notes}

\footnotetext{
${ }^{1}$ Phase II of the study involved two separate sets of interviews with individual athletes, one set focusing on disordered eating and the other on sexual harassment and abuse. Concerning sexual harassment different results from phase I have already been published (Fasting et al., 2003), as has one article based on phase II (Fasting et al., 2002).

${ }^{2}$ The research project was chaired by professor Jorunn Sundgot-Borgen, and was a part of a project named 'the Norwegian Women Project' run by 'Olympiatoppen', which is a division within the Norwegian Olympic Committee. The overall goal of the project, which was running from 1995-2000, was to increase the share of female leaders, coaches and other team supporters to 20 percent in the Olympic Games in Nagano (1998) and Sydney (2000) as well as to improve the quality of female participants in top-level sports in order to increase the number of medals won internationally.
} 
3 'Authority figures in sport' is a translation from the Norwegian concept 'støtteapparatet'. It can also be translated as 'support personnel'. It means those persons who surround an elite athlete, including first of all the coach but also the medical doctor and the trainer, sport leaders ${ }_{2}$ etc.

${ }^{4}$ Interviews done by Kari Fasting and Jorunn Sundgot-Borgen confirm the hypotheses about underreporting.

${ }^{5}$ Survey results were entered on SPSS.X for Windows and descriptive statistics and crosstabulations were generated.

\section{References}

Brackenridge, C.H. (2001) Spoilsports: Understanding and preventing sexual exploitation in sport. London: Routledge.

Brackenridge, C.H. (1997) “"He owned me basically...”: Women’s experiences of sexual abuse in sport', International Review for the Sociology of Sport 32(2):115-130.

Brackenridge, C.H. and Alderson, G.J.K. (1983) 'The implications of sport classification for sport science', proceedings of the Sport and Science Conference of the British Association of Sport Sciences, London, $17-19^{\text {th }}$ Sep.

Cense, M. (1997) Red Card or Carte Blanche: Risk factors for sexual harassment and sexual abuse in sport: Summary, conclusions and recommendations. Arnhem: NOC and NSF.

Cense, M. and Brackenridge, C.H. (200?) 'Temporal and developmental risk factors for sexual harassment and abuse in sport', European Physical Education Review 7(1): 61-79.

Curry, T. (1991) 'Fraternal bonding in the locker room: A pro-feminist analysis of talk about competition and women', Sociology of Sport Journal 15(3):205-215.

Dagsavisen (2004) 'Blatter: Spill i tights’, www.dagsavisen.no/sport/2004/01/774755.shtml 14th Jan.

Grauerholz, E. (1996) 'Sexual harassment in the academy: The case for women professors', in M.S. Stockdale (ed) Sexual Harassment in the Workplace: Perspectives, frontiers, and response strategies. Women and Work 5, London: Sage.

Griffin, P. (1998) Strong Women, Deep Closets: Lesbians and homophobia in sport. Champaign, IL: Human Kinetics.

Holman, M. (1995) 'Female and male athletes' accounts and meanings of sexual harassment in Canadian interuniversity athletics', unpublished PhD thesis, University of Windsor, Ontario, Canada.

Kenyon, G.S. (1968) 'A conceptual model for characterizing physical activity’, in J.W. Loy and Kenyon, G.S. (1969) Sport, Culture and Society: A reader on the sociology of sport. London: Macmillan, pp.71-81. 
Kirby, S. and Greaves, L. (1996) 'Foul play: Sexual abuse and harassment in sport', paper presented to the Pre-Olympic Scientific Congress, Dallas, USA, 11-14 July.

Kirby, S., Greaves, L. and Hankivsky, O. (2000) The Dome of Silence: Sexual harassment and abuse in sport. London: Zed Books.

Leahy, T., Pretty, G. and Tenenbaum, G. (2002) 'Prevalence of sexual abuse in organised competitive sport in Australia’, Journal of Sexual Aggression 8(2):16-36.

Lensky, H. (1986) Out of Bounds: Women, Sport and Sexuality, Toronto: The Women's Press.

Mauldon, E. and Redfern, E. (1981) Games Teaching. $2^{\text {nd }}$ Ed. Macdonald \& Evans.

Messner, M. (1992) Power at Play: Sports and the problem of masculinity. Boston: Beacon Press.

Messner, M. and Sabo, D. (eds.) (1994) Sport, Men and the Gender Order. Champaign IL: Human Kinetics.

Metheney, E. (1963) 'This “thing” called sport', in E. Gerber (ed) (1972) Sport and the Body: A philosophical symposium. Philadelphia: Lea \& Febiger, pp.23-24.

O’Donohue, W. (ed) (1997) Sexual Harassment: Theory, research and treatment. London: Allyn \& Bacon.

Robinson, L. (1998) Crossing the Line: Sexual harassment and abuse in Canada's national sport. Toronto: McLelland and Stewart Inc.

Sparkes, D. (1999) Personal communication, seminar on child protection in sport, NSPCC National Training Centre, Leicester, England, 1-2 Dec.

Stockdale, M.S. (1986) Sexual Harassment in the Workplace: Perspectives, frontiers, and response strategies. Women and Work 5, London: Sage.

Thomas, A.M . (1997) 'Men behaving badly? A psycho-social exploration of the cultural context of sexual harassment' in A. M. Thomas and C. Kitzinger (eds) Sexual Harassment: Contemporary feminist perspectives. Buckingham: Open University Press. pp.131-154.

Tomlinson, A. and Yorganci, I. (1997) 'Male coach/female athlete relations: Gender and power relations in competitive sport’, Journal of Sport and Social Issues 21(2): 134-55.

Tomlinson, P. and Strachan, D. (1996) Power and Ethics in Coaching. Ottawa: Coaching Association of Canada.

Volkwein, K., Schnell,F., Sherwood, D. and Livezey, A. (1997) 'Sexual harassment in sport: Perceptions and experiences of American female student-athletes', International Review for the Sociology of Sport 23(3):283-95. 
Wise, S. and Stanley, L. (1987) Georgie Porgie: Sexual harassment in everyday life. London: Pandora. 
Table 1 Grouping of sports across the four criteria

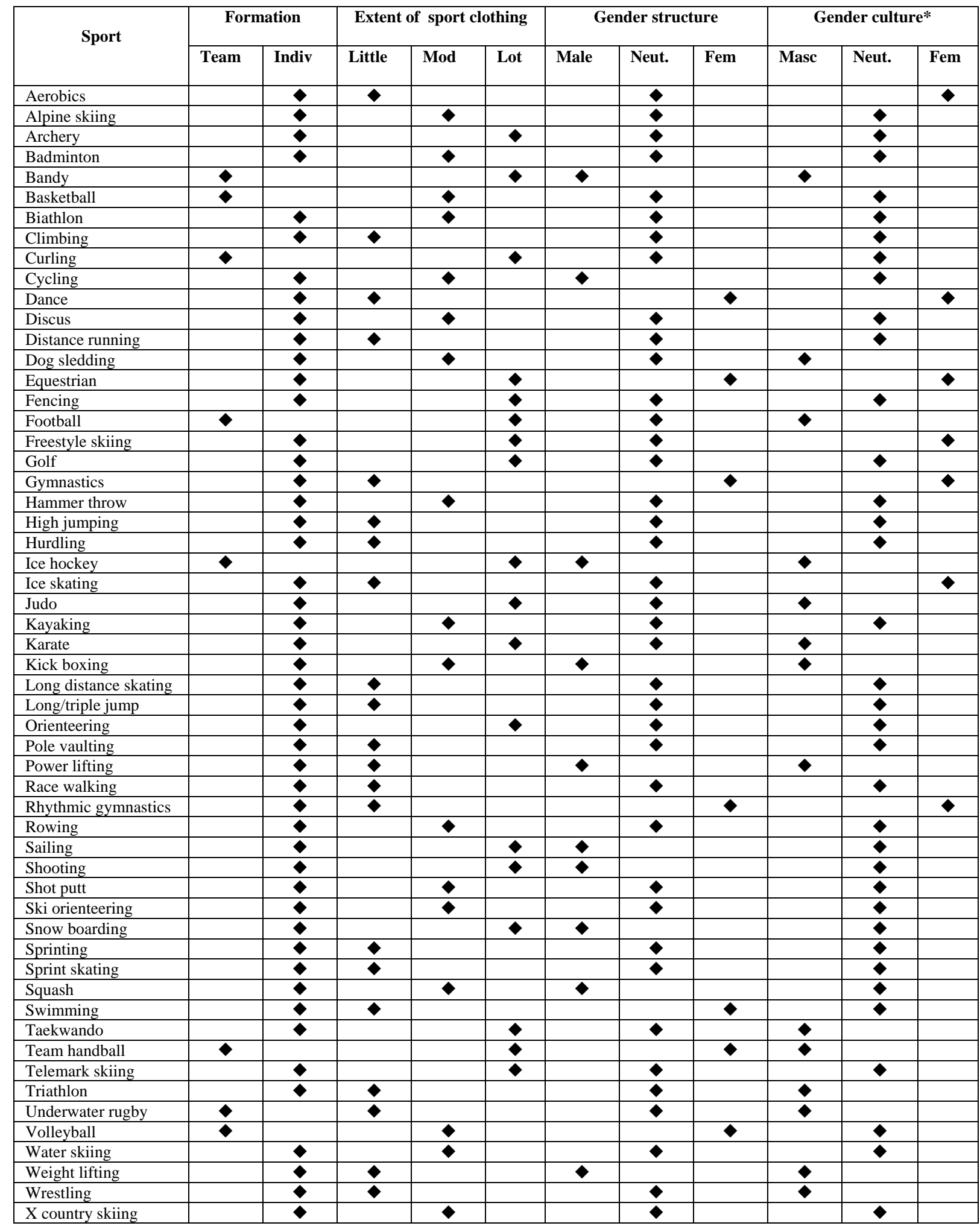

* Based on Koivula (1995) 'Ratings of Gender Appropriateness of Sports Participation:

Effects of Gender-Based Schematic Processing’, Sex Roles, 33(7/8):543-557. 
Table 2a Prevalence of sexual harassment of female athletes, perpetrated inside and outside sport, in team and individual sports

\begin{tabular}{|c|c|c|c|c|c|c|}
\hline \multirow{2}{*}{$\begin{array}{l}\text { Sport } \\
\text { group }\end{array}$} & \multicolumn{2}{|c|}{ In sport } & \multicolumn{2}{|c|}{ Outside sport } & \multicolumn{2}{|c|}{ Any } \\
\hline & $\mathbf{n}$ & $\%$ & $\mathbf{n}$ & $\%$ & $\mathbf{n}$ & $\%$ \\
\hline Team & 62 & 25 & 106 & 43 & 126 & 51 \\
\hline Individual & 94 & 31 & 112 & 36 & 158 & 51 \\
\hline Total & 156 & 28 & 218 & 39 & 284 & 51 \\
\hline Significance & & & & & & \\
\hline
\end{tabular}

Table 2b Prevalence of sexual harassment of female athletes, perpetrated by authority figures and peers, in team and individual sports

\begin{tabular}{l|c|c|c|c|}
\multicolumn{1}{c|}{$\begin{array}{c}\text { Sport } \\
\text { group }\end{array}$} & $\mathbf{n}$ & $\mathbf{0}$ & $\mathbf{n}$ & $\%$ \\
\hline Team & 28 & 11 & 45 & 18 \\
Individual & 52 & 17 & 59 & 19 \\
\hline Total & 80 & 15 & 104 & 19 \\
Significance & \multicolumn{2}{|c|}{ ns (0.07) }
\end{tabular}


Table 3a Prevalence of sexual harassment of female athletes, perpetrated inside and outside sport, in sports with different clothing cover

\begin{tabular}{|c|c|c|c|c|c|c|}
\hline \multirow{2}{*}{$\begin{array}{l}\text { Degree of } \\
\text { clothing } \\
\text { cover }\end{array}$} & \multicolumn{2}{|c|}{ In sport } & \multicolumn{2}{|c|}{ Outside sport } & \multicolumn{2}{|c|}{ Any } \\
\hline & $\mathbf{n}$ & $\%$ & $\mathbf{n}$ & $\%$ & $\mathbf{n}$ & $\%$ \\
\hline Little & 42 & 27 & 48 & 38 & 82 & 53 \\
\hline Moderate & 47 & 27 & 72 & 38 & 81 & 46 \\
\hline Lot & 67 & 30 & 98 & 41 & 121 & 55 \\
\hline Total & 156 & 28 & 218 & 39 & 284 & 51 \\
\hline Significance & \multicolumn{2}{|c|}{ ns } & \multicolumn{2}{|c|}{ ns } & \multicolumn{2}{|c|}{ ns } \\
\hline
\end{tabular}

Table 3b Prevalence of sexual harassment of female athletes, perpetrated by authority figures and peers, in sports with different clothing cover

\begin{tabular}{|c|c|c|c|c|}
\hline \multirow{2}{*}{$\begin{array}{c}\text { Degree of } \\
\text { clothing } \\
\text { cover }\end{array}$} & \multicolumn{2}{|c|}{ From authority figures } & \multicolumn{2}{|c|}{ From peer athletes } \\
\hline & $\mathbf{n}$ & $\%$ & $\mathbf{n}$ & $\%$ \\
\hline Little & 24 & 15 & 25 & 16 \\
\hline Moderate & 28 & 16 & 29 & 17 \\
\hline Lot & 28 & 13 & 50 & 23 \\
\hline Total & 80 & 15 & 104 & 19 \\
\hline Significance & & & & \\
\hline
\end{tabular}


Table 4a Prevalence of sexual harassment of female athletes, perpetrated inside and outside sport, in different organizational gender structures

\begin{tabular}{|c|c|c|c|c|c|c|}
\hline \multirow{2}{*}{$\begin{array}{c}\text { Gender } \\
\text { structure }\end{array}$} & \multicolumn{2}{|c|}{ Inside sport } & \multicolumn{2}{|c|}{ Outside sport } & \multicolumn{2}{|c|}{ Any } \\
\hline & $\mathbf{n}$ & $\%$ & $\mathbf{n}$ & $\%$ & $\mathbf{n}$ & $\%$ \\
\hline $\begin{array}{l}\text { Male- } \\
\text { dominated } \\
\text { Neutral }\end{array}$ & 37 & 36 & 49 & 47 & 62 & 60 \\
\hline $\begin{array}{l}\text { Female- } \\
\text { dominated }\end{array}$ & 26 & 25 & 39 & 38 & 50 & 49 \\
\hline $\begin{array}{l}\text { Total } \\
\text { Significance }\end{array}$ & 156 & 28 & 218 & 39 & 284 & 51 \\
\hline
\end{tabular}

Table 4b Prevalence of sexual harassment of female athletes perpetrated by authority figures and peers in different organizational gender structures

\begin{tabular}{|c|c|c|c|c|}
\hline \multirow{2}{*}{$\begin{array}{c}\text { Gender } \\
\text { structure }\end{array}$} & \multicolumn{2}{|c|}{ By authority figures } & \multicolumn{2}{|c|}{ By peer athletes } \\
\hline & $\mathbf{n}$ & $\%$ & $\mathbf{n}$ & $\%$ \\
\hline $\begin{array}{l}\text { Male- } \\
\text { dominated } \\
\text { Neutral }\end{array}$ & 17 & 16 & 30 & 29 \\
\hline $\begin{array}{l}\text { Female- } \\
\text { dominated }\end{array}$ & 21 & 20 & 7 & 7 \\
\hline Total & 80 & 15 & 104 & 19 \\
\hline Significance & \multicolumn{2}{|c|}{ ns $(0.094)$} & \multicolumn{2}{|c|}{0.000} \\
\hline
\end{tabular}


Table 5a Prevalence of sexual harassment of female athletes, perpetrated inside and outside sport, in different organizational gender cultures

\begin{tabular}{|c|c|c|c|c|c|c|}
\hline \multirow{2}{*}{$\begin{array}{l}\text { Gender } \\
\text { culture }\end{array}$} & \multicolumn{2}{|c|}{ In sport } & \multicolumn{2}{|c|}{ Outside sport } & \multicolumn{2}{|c|}{ Any } \\
\hline & $\mathbf{n}$ & $\%$ & $\mathbf{n}$ & $\%$ & $\mathbf{n}$ & $\%$ \\
\hline Masculine & 68 & 31 & 104 & 48 & 129 & 59 \\
\hline Neutral & 73 & 26 & 92 & 33 & 127 & 46 \\
\hline Feminine & 15 & 27 & 22 & 39 & 28 & 50 \\
\hline Total & 156 & 28 & 218 & 39 & 284 & 51 \\
\hline Significance & \multicolumn{2}{|c|}{ ns } & \multicolumn{2}{|c|}{0.005} & \multicolumn{2}{|c|}{0.013} \\
\hline
\end{tabular}

Table 5b Prevalence of sexual harassment of female athletes, perpetrated by authority figures and peers, in different organizational gender cultures

\begin{tabular}{|c|c|c|c|c|}
\hline \multirow{2}{*}{$\begin{array}{l}\text { Gender } \\
\text { culture }\end{array}$} & \multicolumn{2}{|c|}{ By authority figures } & \multicolumn{2}{|c|}{ By peer athletes } \\
\hline & $\mathrm{n}$ & $\%$ & $\mathbf{n}$ & $\%$ \\
\hline Masculine & 32 & 15 & 50 & 23 \\
\hline Neutral & 36 & 13 & 49 & 18 \\
\hline Feminine & 12 & 21 & 5 & 9 \\
\hline Total & 80 & 15 & 102 & 10194 \\
\hline Significance & & & & \\
\hline
\end{tabular}

